\title{
EDUCAÇÃO E GESTÃO SOCIOAMBIENTAL ${ }^{1}$
}

\author{
Daniele Freire Procópio ${ }^{2}$ \\ Paula Rafaela Leite Carvalho ${ }^{3}$ \\ Mônica Maria Vieira Lima Barbosa ${ }^{4}$
}

\section{RESUMO}

O presente artigo tem como objetivo esclarecer, por meio do estudo das obras de Moacir Gadotti (Pedagogia da Terra), Paulo Freire (Pedagogia da Autonomia) e dos PCNs, a temática da Educação e Gestão Socioambiental, no contexto contemporâneo, dentro e fora do âmbito escolar. Procuramos demonstrar como o capitalismo neoliberal, que rege a realidade humana, mantém um elo com a degradação do planeta e como uma prática docente crítica e dialógica

\footnotetext{
${ }^{1}$ Artigo apresentado à disciplina de Educação e Gestão Socioambiental do curso de pedagogia do IV período, da Universidade do Estado da Bahia (UNEB), campus VIII, turno noturno, requerido como atividade avaliativa, sob orientação da professora Mônica. $\mathrm{O}$ artigo tem a finalidade de esclarecer como é possível viabilizar uma consciência planetária por meio da educação emancipadora e crítica.

${ }^{2}$ Pedagoga, especializanda em Metodologia e Docência do Ensino Superior. Instrutora de Educação profissional III - SENAC - BA /Casa do Comércio. E-mail: dfp1986@gmail.com

${ }^{3}$ Pedagoga, especializanda em Educação Especial com ênfase em LIBRAS. Servidora Técnica de Processo III - Professora de Ensino Fundamental do SESC Ler - Paulo Afonso/BA. E-mail: paularafaela_1@hotmail.com

${ }^{4}$ Mestra em Ciências da Educação. Pedagoga. Especialista em Orientação Educacional. Especialista em Ecologia Humana e Gestão Socioambiental. Especializanda em Psicopedagogia. Especilizanda em Gestão e Tutoria Educacional. Professora da Faculdade Sete de Setembro (FASETE). Professora Tutora Externa do Centro Universitário Leonardo da Vinci (UNIASSELVI). Professora da Plataforma Freire - Plano Nacional de Formação de Professores da Educação Básica (PARFOR)/UNEB. Coordenadora do Colégio Sete de Setembro, Paulo Afonso-BA. E-mail: monicamvlb@yahoo.com.br
}

\begin{tabular}{l|l|l|l|l}
\hline Revista Extensão \& Cidadania & Vitória da Conquista & v. 1, n. 2 & p. 125-132 & jul/dez. 2013 \\
\hline
\end{tabular}


pode contribuir para a superação da visão pragmática e acrítica que dirige a educação tradicional mediante um trabalho interdisciplinar e contrahegemônico de educação.

Palavras-chave: Neoliberalismo. Cidadania planetária. Ecopedagogia. Educação Ambiental.

\begin{abstract}
This scientific article has the intent to show per Moacir Gadotti and Paulo Freire literatures and the PCNs a coeval view of the environmental education and management in and out of a scholar behold. Trying so to demonstrate how the neoliberal capitalism, which guides the human reality, have a connection with the planet degradation and, finally, how a critical faculty practice can excel the pragmatic and non-critical views that guides the traditional education by an interdisciplinary and counter-hegemonic education.
\end{abstract}

Keywords: Neoliberalism. Planetary citizenship. Ecopedagogy. Environmental Education.

\title{
1 INTRODUÇÃO
}

A educação emancipadora e planetária pode viabilizar um rompimento com as relações de opressão e de degradação causadas pela globalização excludente regida pelo neoliberalismo que desrespeita os direitos e valores humanos por meio da divisão entre globalizadores e globalizados. Assim, com este artigo pretende-se investigar, com base na autonomia da pedagogia de Paulo Freire, como é possível viabilizar a ecopedagogia defendida por Moacir Gadotti, e a transversalidade proposta pelos Parâmetros Curriculares Nacionais (PCNs). Desse modo, o foco será a valorização de uma educação socioambiental que seja contra-hegemônica e que de maneira interdisciplinar possa despertar os discentes para a sustentabilidade, através de uma prática docente capaz de romper com os valores de dominação e que oriente os educandos a pensar epistemologicamente sobre a Terra. 


\section{REVISÃO DE LITERATURA}

\subsection{Possibilidades e desafios para uma educação sustentável}

No contexto da globalização, o pobre é quem mais sofre os danos causados pelo crescimento descomunal e pelas mazelas do planeta. $\mathrm{O}$ modelo econômico vigente segrega as pessoas e a globalização destrói a diversidade cultural, sobrepondo uma cultura a outra, destruindo a identidade de muitos povos e deixando à margem do desenvolvimento quem não pode consumir os bens que a globalização fornece.

O discurso da globalização que fala da ética esconde, porém, que a sua é a ética do mercado e não a ética universal do ser humano, pela qual devemos lutar bravamente se optarmos, na verdade, por um mundo de gente. $\mathrm{O}$ discurso da globalização astutamente oculta ou nela busca penumbrar a reedição intensificada ao máximo, mesmo que modificada, de medonha malvadez com que o capitalismo aparece na História. O discurso ideológico da globalização procura disfarçar que ela vem robustecendo a riqueza de uns poucos e verticalizando a pobreza e a miséria de milhões. O sistema capitalista alcança no neoliberalismo globalizante o máximo de eficácia de sua intrínseca (FREIRE, 1996, p. 144).

É preciso atentar para uma educação que viabilize justiça social, pois a ideologia dominante consegue, por meio da escola, disseminar uma educação acrítica. O projeto ecopedagógico deve ser diferente do projeto neoliberal, deve estar em parceria com entidades fora das escolas, e, nesse processo, as ONGs são as representantes da sociedade civil.

Segundo Gadotti (2000), os nossos problemas atuais têm suas raízes profundas na nossa maneira de viver, e a escola, como disseminadora das práticas neoliberais de sociedade, atua como elemento ecoador, pois, com base em seu currículo, ela consegue fazer valer a ideologia das classes que estão no poder e que não sofrem no dia a dia com a degradação do planeta. Por isso, é preciso pensar um modelo de educação que rompa com os valores da classe dominante 
e produza uma visão de totalidade, no qual os princípios de tolerância promovam a conscientização de que todos nós somos moradores da "casa terra" e que estamos destruindo a capacidade que a mesma tem de sustentar a vida, o que prejudica o nosso bem-estar, por causa da busca de crescimento econômico e consumo material. Para tal, a nova educação deve ser fundamentada na política de participação. Política que proporciona às pessoas o sentimento de coletividade, o interesse $\mathrm{e}$ a responsabilidade por tudo que representa o interesse comum.

Com base em uma educação problematizadora, busca-se fazer com que os homens e mulheres do planeta se percebam como sujeitos históricos, a fim de exercerem plenamente a sua cidadania planetária. Assim, a educação ambiental torna-se um meio de viabilizar a tomada de consciência das mazelas do mundo, estabelecendo a noção de que todos os seres humanos estão inextricavelmente interligados.

De acordo com os PCNs (BRASIL, 1998, p. 187), “a principal função do trabalho com o tema Meio Ambiente é contribuir para a formação de cidadãos conscientes, aptos a decidir e atuar na realidade socioambiental de um modo comprometido com a vida, com o bemestar de cada um e da sociedade, local e global", pois há um abismo que separa as criações humanas dos sistemas ecologicamente sustentáveis da natureza. Busca-se, então, por intermédio da educação que é um ato eminentemente político, logo, impossível de ser neutra, como defendia Paulo Freire (1996): o desenvolvimento da postura crítica dos alunos possibilitada por meio do trabalho docente interdisciplinar, que possibilite a transformação dos conceitos, a explicitação de valores e a inclusão de procedimentos, sempre vinculados à realidade, a fim de formar cidadãos mais ativos democraticamente.

Educar para a cidadania planetária implica muito mais do que uma filosofia educacional, do que o enunciado de seus princípios. A educação para a cidadania planetária implica uma revisão de nossos currículos, uma reorientação de nossa visão de mundo da educação como espaço de inserção do individuo não numa comunidade local, mas numa comunidade que é local e é global ao mesmo tempo. Educar então não seria como 
Émile Durkheim, a transmissão da cultura de uma geração para outra, mas a grande viagem de cada indivíduo no seu universo interior e no universo que o cerca (GADOT'TI, 2000, p. 142).

2.2 Educação ambiental e ecopedagogia

A ecopedagogia nasceu da educação ambiental, mas tomou um sentido mais amplo na medida em que transpôs o âmbito escolar e se tornou uma pedagogia para a vida. Desse modo, trouxe uma macrovisão de homem e de mundo, rompendo assim com a visão pragmática de educação tradicional.

Ainda como antigamente, as escolas hoje ensinam conteúdos completamente desvinculados da realidade mundial. Os docentes não educam e não reeducam a sua prática, o que, muitas vezes, torna a escola um espaço de "não saber". A escola cidadã e a ecopedagogia requer um docente que se perceba como ser inacabado e que deve proporcionar aos educandos uma educação contra o autoritarismo e "contra a ordem capitalista vigente que inventou esta aberração: a miséria na fartura” (FREIRE, 1996, p. 115).

Não há docência sem discência, as duas se explicam e seus sujeitos, apesar das diferenças que os conotam, não se reduzem à condição de objeto, um do outro. Quem ensina aprende ao ensinar e quem aprende ensina ao aprender. Quem ensina alguma coisa a alguém (FREIRE, 1996, p. 25).

A partir do momento em que se esquece que a escola está inserida na sociedade, a mesma torna-se um "não lugar", por isso é preciso transformá-la em espaço de sociabilidade e de tolerância com a Terra e com os homens e as mulheres. O primeiro passo para isto é uma alfabetização ecológica. Segundo Paulo Freire (1996), o professor deve se assumir como ser ético, para que sua prática traduza sua essência, pois o seu discurso não pode ser diferente da sua prática, com o objetivo de que mais do que nunca, possa promover e instaurar a "ética universal do ser humano" (FREIRE, 1996, p. 9) que é indispensável à convivência humana. 
O educador democrático deve ensinar os educandos a pensar certo, um pensar crítico e transformador, pois "educar é substantivamente formar" (FREIRE, 1996, p. 37). Assim, poderá ocorrer uma abertura para um novo pensar, um pensar que traz em seu âmbito a consciência da planetariedade, que desperta as pessoas para a imoralidade das misérias do mundo. Assim, a ecopedagogia nasce da relação democrática e solidária, pois essa nova pedagogia centra-se na relação entre sujeitos que aprendem juntos e que rompem a competitividade da pedagogia tradicional. $\mathrm{Na}$ ecopedagogia, a ética se faz como o cerne do trabalho docente e a cidadania como o eixo da educação, firmando-se uma na outra. Isto está em comunhão com as ideias de Paulo Freire, quando afirma que a ética é profundamente transformadora. Por ser uma pedagogia multicultural, a mesma é contrária à monocultura gerada pela globalização.

A ecopedagogia propõe um novo currículo com foco nos princípios da sustentabilidade e da emancipação, este último pressupondo uma repolitização global da vida coletiva, pois a preservação do meio ambiente depende de uma consciência ecológica e a formação da consciência depende da educação. Dessa maneira, fazse uma pedagogia para a promoção da aprendizagem com base na vida cotidiana.

As pedagogias clássicas eram antropocêntricas. A ecopedagogia parte de uma consciência planetária (gênero, espécies, reinos, educação formal, informal e não formal). Ampliamos o nosso ponto de vista. Do homem para o planeta, acima de gêneros, espécies e reinos. De uma visão antropocêntrica para uma consciência planetária, para uma prática de cidadania planetária e para uma nova referência ética e social: a civilização planetária (GADOTTI, 2000, p. 176).

Segundo Gadotti (2000), as escolas devem superar o pensamento cartesiano e substituí-lo pela transdisciplinaridade. Ele afirma que as escolas têm sido representantes das ideias sobre o meio ambiente, por mais que a ecopedagogia tenha perpassado a educação ambiental 
escolar. Ao contrário da visão ambientalista, a ecopedagogia insere a sociedade dentro da natureza. A qualidade de vida expressa nos PCNs (BRASIL, 1998) está ligada ao meio ambiente e a qualidade de vida da ecopedagogia pressupõe mudanças no campo social, cultural, econômico de gênero e da terra, ou seja, pressupõe mudança na ideia de relações sociais e ambientais. Ainda segundo os PCNs (BRASIL, 1998), em consonância com Gadotti reforça que a globalização econômica gera a globalização dos problemas ambientais.

Os PCNs (BRASIL, 1998) contemplam a educação socioambiental com base na transversalidade, deixando claro que a mesma requer um conhecimento crítico contrário à "prática bancária" (FREIRE, 1996, p. 28), mas Gadotti (2000) sustenta que a educação para a sustentabilidade não pode ser confundida com educação escolar, ela apenas contribui para a consciência da degradação do planeta. Ele ainda sustenta a modificação de um currículo escolar que seja significativo para os alunos e também para o planeta. Nesse processo entram os temas transversais propostos pelos PCNs (BRASIL, 1998) que alertam os alunos sobre as questões ambientais. Eles requerem dos alunos uma visão global dos problemas do ambiente mediante transversalidade, à medida que o professor consegue unir questões ambientais a sua área de atuação, conseguindo, assim, trabalhar o local sem perder de vista o global. De acordo com Gadotti (2000, p. 141), "os currículos escolares, numa visão ecopedagógica, deverão incluir, desde os estudos infantis, não apenas o estudo do ambiente natural, o entorno, os contextos urbanos, mas a história da Terra e do universo. A ecopedagogia nos ensina a olhar para o céu".

\section{CONSIDERAÇÕES FINAIS}

A autonomia da pedagogia de Paulo Freire (1996) incita os professores a mudanças atitudinais, pois modifica a teoria tradicional enraizada nos pressupostos do neoliberalismo - individualista e segregador. Dessa maneira, a pratica é pautada nos ideais de que ensinar é uma especificidade humana, a educação é um ato de intervenção no mundo; ensinar não é transferir conhecimento, é preciso que haja 
intencionalidade e criticidade, além de ser um ato político. Assim, por meio dessa visão de educação surgiu a ecopedagogia, defendida por Moacir Gadotti (2000) como uma forma de superar a visão ambientalista fragmentada, na qual pensar ecologicamente vai muito além de atitudes simplórias de preservação do ambiente, pois a ecopedagogia apresenta uma concepção holística e sistêmica de homem em comunhão com a Terra.

A ecopedagogia busca conscientizar as pessoas quanto a sua relação com meio ambiente, a fim de que elas mudem suas ações com base em uma nova concepção de mundo fornecida pela educação emancipadora e ecológica (ecoalfabetização) e respaldada pelos PCNs (BRASIL, 1998), que afirmam que as escolas devem trabalhar o desafio da transversalidade como base para a conscientização dos alunos. Assim, mediante essa mudança de concepção de mundo, pautada na emancipação pedagógica de Paulo Freire (1996), torna-se possível pensar uma nova escola e nela um novo mundo. Isto é possível a partir de um currículo estabelecido com as demandas atuais e com as mazelas do mundo, para que acorde os seres humanos para uma nova realidade, na qual possamos viver como em uma comunidade global e estejamos todos interligados.

\section{Referências}

BRASIL. Ministério da Educação. SEC. Parâmetros Curriculares Nacionais: terceiro e quarto ciclos/temas transversais: Brasília, 1998.

FREIRE, Paulo. Pedagogia da autonomia: saberes necessários à pratica educativa. São Paulo: Paz e Terra, 1996.

GADOTTI, Moacir. Pedagogia da terra. 5. ed. São Paulo: Petrópolis, 2000. 